Case Study

\title{
Synergistic effects of vacuum therapy and laser therapy on physical rehabilitation
}

\author{
Larissa Aparecida Biason Lopes, RPT ${ }^{1)}$, Carolina Alvarez, RPT ${ }^{1}$,

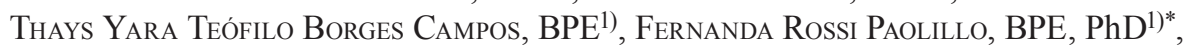 \\ Vanderlei Salvador Bagnato, BS, PhD ${ }^{1)}$ \\ 1) Optics Group from São Carlos Institute of Physics, University of São Paulo: \\ Av. Trabalhador Sãocarlense, 400 Centro, CEP 13560-970, São Carlos, SP, Brazil
}

\begin{abstract}
Purpose] This study aims to evaluate the synergistic effects of laser therapy and vacuum therapy in the rehabilitation of some disorders of the osteomuscular articular system (shoulder bursitis, low back pain, hip dysfunction after long-term impact of femoral endoprosthesis). [Participants and Methods] Three case reports were described. A vacuum laser system was used, which is a device that contains 1 handpiece with 3 red lasers $(660 \mathrm{~nm})$ and 3 infrared lasers $(808 \mathrm{~nm})$. This device contains 6 laser beams that are arranged around the vacuum chamber bore which generate negative pressure. Two weekly sessions were held, totalling 10 treatment sessions. Active goniometry was performed to assess range of motion (ROM) of the shoulder, lumbar spine and hip, and visual analogue scale (VAS) was used to evaluate pain in the pre and posttreatment period. [Results] There was a pain reduction and an increase in ROM in the different clinical cases. [Conclusion] Potentiating laser therapy through suctioning during the rehabilitation process leads to pain relief and increased functionality.

Key words: Vacuum therapy, Laser therapy, Physical rehabilitation
\end{abstract}

(This article was submitted Nov. 14, 2018, and was accepted Feb. 8, 2019)

\section{INTRODUCTION}

Disorders of the osteomuscular articular system, such as shoulder bursitis, low back pain and hip dysfunction, cause pain and loss of range of motion (ROM) because movements are consciously or unconsciously avoided for protection, which results in the gradual impairment of muscle function. In this context, physical and non-pharmacological agents are essential for pain reduction and increasing functionality ${ }^{1,2)}$.

Vacuum therapy has been used for a long time (approximately since 1500 BC), in which Egyptian images sculpted in temples show the technique, which combines the positive pressure of blood with the negative pressure of the vacuum, favoring various therapeutic effects, among them the anti-inflammatory and analgesic action, as well as lymphatic drainage. It also has similar effects to manual massages, however it is faster and more standardized. High values of negative pressures and prolonged application times can generate edema, erythema and ecchymosis in a circular pattern, but these adverse effects disappear in a few minutes or a few days ${ }^{3,4}$.

Laser is an acronym for Light Amplification by Stimulated Emission of Radiation. Laser therapy advanced significantly in the mid-1960s and to date has been used in the health area, such as medicine, dentistry and physiotherapy producing satisfactory results in treatments that require, for example, anti-inflammatory and analgesic action, as well as acceleration of tissue healing processes ${ }^{5-7)}$. Penetration of skin by light depends on the incident wavelength and optical properties of the biological tissues. The most used wavelengths in rehabilitation are: red $(660 \mathrm{~nm})$ and infrared $(808 \mathrm{~nm})$, as they allow greater tissue penetration compared to other wavelengths, e.g. blue, green, amber and violet. Moreover, infrared radiation reaches

*Corresponding author: Fernanda Rossi Paolillo (E-mail: fer.nanda.rp@hotmail.com)

(C2019 The Society of Physical Therapy Science. Published by IPEC Inc.

(c) (1) $\odot$ This is an open-access article distributed under the terms of the Creative Commons Attribution Non-Commercial No Derivatives

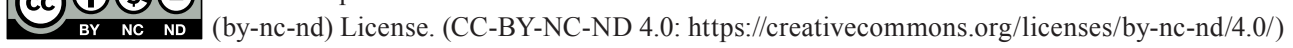


greater depths compared to red light ${ }^{8,9)}$.

Vacuum therapy and laser therapy are often used in rehabilitation processes, however the synergistic application of these therapies has not yet been demonstrated.

This study aims to investigate the synergistic effects of vacuum therapy and laser therapy on pain and ROM in different clinical cases.

\section{PARTICIPANTS AND METHODS}

This study was approved by the São Carlos Hospital Research Ethics Committee (approval no. 058/16). Patients from the Phototherapy \& Photodynamic Therapy Center at the São Carlos Institute of Physics (IFSC) at the University of São Paulo (USP), who were treated with vacuum and laser therapy, were asked to participate in the case study. These patients were referred by physicians in private practices or public service for treatment in this center at IFSC-USP. A medical referral diagnosis was used for all cases. The participants signed a written informed consent before their participation in the study. Data collection and treatments were performed by physical therapists.

Initially, an anamnesis and a brief physical examination with anthropometric data (body weight and height) were performed to provide personal data. Anthropometric data were used to determine the body mass index [BMI, body weight (kg) divided by height $\left.(\mathrm{m})^{2}\right]$.

For treatment, the vacuum laser system (Fig. 1) was developed by researchers from the optics group at IFSC-USP in partnership with MM Optics (MMO, São Carlos, SP, Brazil). The vacuum laser system is a combination therapy device consisting of 1 handpiece with 6 diode lasers [3 red lasers $(660 \mathrm{~nm})$ and 3 infrared lasers $(808 \mathrm{~nm})$ ] arranged around the vacuum chamber bore which generate negative pressure. Each laser was calibrated to generate a $100 \mathrm{~mW}$ average power. Lasers are applied in continuous mode and non-contact mode. Furthermore, the wavelength of the laser to be used (red and/ or infrared) can be selected. The vacuum pressure ranges from 0 to $-500 \mathrm{mbar}$ (or $\mathrm{mmHg}$ ) and can be used in continuous and pulsed mode. There are 9 different settings in the pulsed mode that vary depending on the pulse rate. Different suction cup sizes $(160 \mathrm{~mm}, 100 \mathrm{~mm}, 60 \mathrm{~mm}$ and $40 \mathrm{~mm}$ ) can be used depending on the body area and application site.

In order to carry out the treatments, grapeseed oil was applied on the skin, making it easier to slide the handpiece around. The treatments with vacuum laser system (Fig. 2) were performed twice a week, making a total of 10 sessions.

The patients were instructed not to exercise or not to take analgesics prior the evaluations and during the treatment. Evaluations and treatments were carried out on different days and in a laboratory with controlled temperature $\left(22-23^{\circ} \mathrm{C}\right)$ and relative humidity between $50 \%$ and $60 \%$.

All evaluations were performed in the pre- and post-treatment period, at rest and non-painful stimuli. The evaluations were: (i) Active goniometry was performed to assess range of motion (ROM) of the shoulder, lumbar spine and hip and; (ii) Visual Analogue Scale (VAS) to assess pain.

The percent changes in ROM and pain score between the situations pre- and post-treatment were determined using the following formula: delta=[(final value - initial value/initial value $) \times 100]$.

\section{CASE DESCRIPTION}

Case 1 presentation-Shoulder Bursitis: a 49-year-old female patient (weight: $72 \mathrm{~kg}$, height: $1.60 \mathrm{~m}$ and BMI: 28.1), has had subacromial bursitis on the right and left sides for two years, with severe pain radiating into the arm and loss of ROM. However, the patient did not present any associated pathologies, she did not take analgesics and did not practice physical activity. Clinical protocol: concerning the laser parameters, the red and infrared radiation with a $100 \mathrm{~mW}$ average power was used in the non-contact mode simultaneously with the suction. Vacuum therapy in the continuous mode was performed at 4
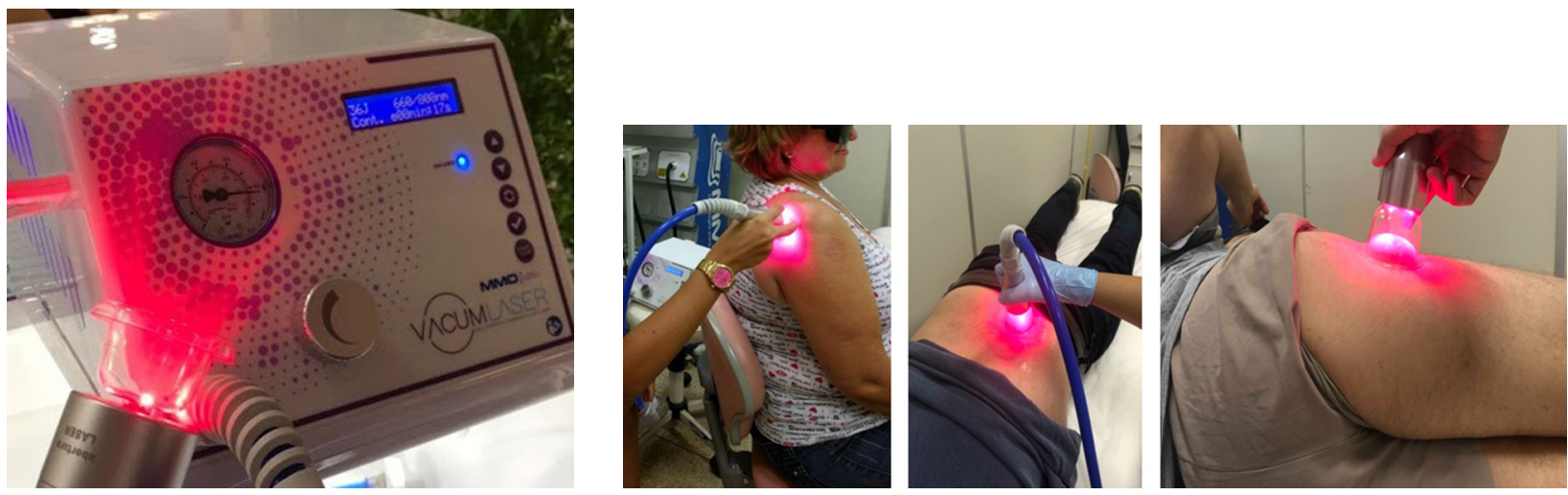

Fig. 1. The vacuum laser system.

Fig. 2. Clinical procedures. 
Table 1. Results of case report 1: range of motion and pain score of shoulders

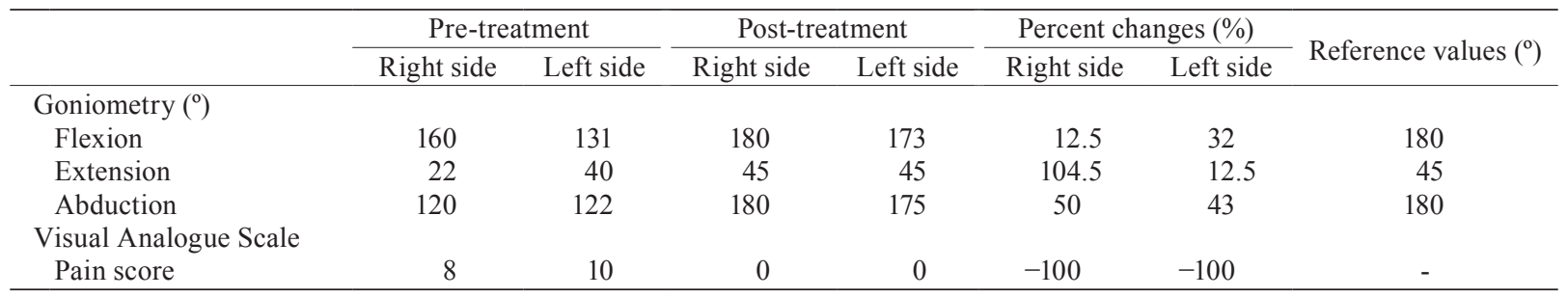

Table 2. Results of case 2: range of motion and pain score of lumbar

\begin{tabular}{lcccc}
\hline & Pre-treatment & Post-treatment & Percent changes $(\%)$ & Reference values $\left(^{\circ}\right)$ \\
\hline Goniometry $\left(^{\circ}\right)$ & & & & \\
$\quad$ Flexion & 42 & 62 & 48 & 95 \\
Extension & 18 & 22 & 22 & 35 \\
Right side flexion & 21 & 35 & 67 & 40 \\
$\quad$ Left side flexion & 21 & 33 & 57 & 40 \\
Visual Analogue Scale & & & -100 & - \\
$\quad$ Pain score & 8 & 0 & & \\
\hline
\end{tabular}

Table 3. Results of case 3: range of motion and pain score of hip

\begin{tabular}{lcccc}
\hline & Pre-treatment & Post-treatment & Percent changes (\%) & Reference values $\left(^{\circ}\right)$ \\
\hline Goniometry $\left(^{\circ}\right)$ & & & & \\
Flexion & 120 & 124 & 3 & 125 \\
Extension & 9 & 9 & 0 & 10 \\
Abduction & 40 & 41 & 2.5 & 45 \\
$\quad$ Adduction & 12 & 13 & 8 & 15 \\
Visual Analogue Scale & & & -100 & - \\
$\quad$ Pain score & 8 & 0 & & \\
\hline
\end{tabular}

points on the deltoid muscle lasting 1 minute per point with a pressure of -200 mbar and then in the scanning mode, sliding the handpiece towards the muscle fibers with a pressure of -100 mbar lasting 2 minutes. The results of the shoulder bursitis treatment can be observed in Table 1. There was reduced shoulder pain (100\%) and increased shoulder ROM for flexion (right: $12.5 \%$ and left: $32 \%$ ), extension (right: $104.5 \%$ and left: $12.5 \%$ ) and abduction (right: $50 \%$ and left: $43 \%$ ).

Case 2 presentation-Low Back Pain: a 54-year-old male patient (weight: 85 kg, height: 1.73 m and BMI: 28.4) with severe low back pain because of his work which requires great upper limb effort and bimanual load lifting task. The patient reported that he has had severe back pain for 3 years that restricts his daily activities. However, the patient did not present associated pathologies, he did not take analgesics and did not practice physical activity. Clinical protocol: concerning the laser parameters, the red and infrared radiation with a $100 \mathrm{~mW}$ average power was used in the non-contact mode simultaneously with the suction. Vacuum therapy in the continuous mode was performed at 4 points on the lumbar region lasting 2 minutes per point at a pressure of -300 mbar and then in the scanning mode, sliding the handpiece towards the muscle fibers at a pressure of -100 mbar for 2 minutes. The results for low back pain treatment can be seen in Table 2. There was reduced lumbar pain $(100 \%)$ and increased lumbar ROM for flexion (48\%), extension (22\%), left side flexion (67\%) and right side flexion (57\%).

Case 3 presentation-Hip Dysfunction After Long-Term Impact of Femoral Endoprosthesis: a 42-year-old male patient (weight: $80.5 \mathrm{~kg}$, height: $1.69 \mathrm{~m}$ and BMI: 28.2) has hip dysfunction and pain. When he was 16 years old, he fell off his bicycle and fractured his right femur. Aged 31 years old, he underwent surgery to replace the femoral endoprosthesis. Recently, the patient reported acute and constant pain in the surgical region. Moreover, he demonstrated compensatory movements and pathological gait, and also used a walking stick. However, the patient did not take analgesics and did not practice physical activity. Clinical protocol: concerning the laser parameters, a red and infrared radiation with a $100 \mathrm{~mW}$ average power was used in the non-contact mode simultaneously with the suction. Vacuum therapy was performed at 3 points on the hip joint in continuous mode with a pressure of -150 mbar for 3 minutes. The treatment was also performed at 3 points on the lateral thigh region in the pulsed mode ( 50 pulses per minute) with a pressure of -150 mbar for 3 minutes and then in the scanning mode by sliding the handpiece towards the muscle fibers for 5 minutes with a pressure of -100 mbar. The results of the hip treatment can be seen in Table 3. Furthermore, after treatment, the patient stopped using the walking stick. There was reduced hip pain (100\%) and increased hip ROM for flexion (3\%), abduction (2.5\%) and adduction (8\%). In this case, the patient had good ROM, but pain was his main complaint. 


\section{DISCUSSION}

Pain reduction and increased ROM were observed in different clinical cases (shoulder bursitis, low back pain, hip dysfunction after long-term impact of femoral endoprosthesis). These benefits occurred due to the synergistic effects of vacuum therapy and laser therapy in 10 treatment sessions.

There are several therapeutic effects of vacuum therapy ${ }^{3,4)}$, including deep mobilization of the skin, adipose tissue, and vascular and lymphatic structures, as well as the flattening of the epidermis. The vacuum increases the pressure of the capillaries to filter the cellular fluids and residues, decreasing the inflammatory mediators and reducing the connective tissue adhesion. Afterwards, the pressure of the capillaries decreases and there is a movement of filtered fluids towards the treated body site. Thus, vacuum therapy promotes lymphatic drainage eliminating toxins and increasing blood flow, cellular oxygen supply and metabolic activity, as well as venous return. Therefore, vacuum therapy leads to anti-inflammatory and analgesic effects, muscle relaxation and increased ROM. It also accelerates tissue healing and eliminates lactic acid and other metabolites that help post-exercise muscle recovery. These factors may also lead to increased muscle function ${ }^{10-13)}$.

Regarding laser therapy, photophysical, photochemical and photobiological effects can be observed in the biological light-tissue interaction. In the photophysical or photoelectric effect, there is an increase in the transport of electrons in the respiratory chain of the mitochondria and stimulation of adenosine triphosphate (ATP) production for tissue healing. There are also alterations in membrane permeability, contributing to a greater synthesis of $\mathrm{ATP}^{8)}$. Regarding the photochemical and photobiological effects, DNA/RNA gene expression modulation also occurs to increase protein synthesis, accelerating tissue regeneration, such as skin, muscle, bone and peripheral nerves, as well as increased blood flow, synthesis of collagen and anti-inflammatory action with analgesia ${ }^{8,14)}$. The anti-inflammatory and analgesic effects are also related to the modulation of cytokines, prostaglandins, histamine, bradykinin, leukotrienes, serotonin, betaendorphin, cortisol, among others ${ }^{15-17)}$. Another mechanism of pain relief is modulation of nociception ${ }^{1,2)}$.

Techniques used separately may have slower therapeutic responses, and therefore the synergistic use of vacuum therapy with laser therapy may enhance the quality and speed of the biological response in the rehabilitation process. Several studies $^{1,2,7,18)}$ showed that mechanical stimulus such as therapeutic ultrasound ${ }^{1,2)}$ and physical exercise ${ }^{7,18)}$ were associated with laser therapy and showed significant synergistic effects on physical rehabilitation, including pain relief, accelerated tissue repair and increased physical function. Vacuum therapy is also a mechanical stimulus to potentiate laser therapy, leading to synergistic effects. However, in the current study, combined therapy was not compared with laser therapy or vacuum therapy alone. Future studies should explore the limitation of this research and investigate the effects of the laser and vacuum therapies, together and separately, on physical rehabilitation.

This is the first study that shows a new system to promote synergistic applications of vacuum and laser for physical rehabilitation. There was reduced pain and increased ROM during the rehabilitation process. Therefore, this technique is an important non-pharmacological resource which can provide benefits to disorders of the osteomuscular articular system.

\section{Funding}

This study was funded by the São Paulo Research Foundation (FAPESP), grant no. 2013/14001-9 and 2013/07276-1 (CEPOF-CEPID Program).

\section{Conflicts of interest}

All authors confirm that there is no conflict of interest.

\section{REFERENCES}

1) Paolillo AR, Paolillo FR, João JP, et al.: Synergic effects of ultrasound and laser on the pain relief in women with hand osteoarthritis. Lasers Med Sci, 2015, 30: 279-286. [Medline] [CrossRef]

2) Paolillo FR, Paolillo AR, João JP, et al.: Ultrasound plus low-level laser therapy for knee osteoarthritis rehabilitation: a randomized, placebo-controlled trial. Rheumatol Int, 2018, 38: 785-793. [Medline] [CrossRef]

3) El Sayed SM, Mahmoud HS, Nabo MM: Methods of wet cupping therapy (Al-Hijamah): in light of modern medicine and prophetic medicine. Altern Integr Med, 2013, 2: 1-16.

4) Rozenfeld E, Kalichman L: New is the well-forgotten old: the use of dry cupping in musculoskeletal medicine. J Bodyw Mov Ther, 2016, 20: 173-178. [Medline] [CrossRef]

5) Jang H, Lee H: Meta-analysis of pain relief effects by laser irradiation on joint areas. Photomed Laser Surg, 2012, 30: 405-417. [Medline] [CrossRef]

6) Hsieh RL, Lee WC: Short-term therapeutic effects of 890-nanometer light therapy for chronic low back pain: a double-blind randomized placebo-controlled study. Lasers Med Sci, 2014, 29: 671-679. [Medline] [CrossRef]

7) Adabbo M, Paolillo FR, Bossini PS, et al.: Effects of low-level laser therapy applied before treadmill training on recovery of injured skeletal muscle in Wistar rats. Photomed Laser Surg, 2016, 34: 187-193. [Medline] [CrossRef]

8) Karu TI, Pyatibrat LV, Afanasyeva NI: A novel mitochondrial signaling pathway activated by visible-to-near infrared radiation. Photochem Photobiol, 2004, 80: 366-372. [Medline] [CrossRef] 
9) Cotler HB, Chow RT, Hamblin MR, et al.: The use of Low Level Laser Therapy (LLLT) for musculoskeletal pain. MOJ Orthop Rheumatol, 2015 , 2: 00068. [Medline] [CrossRef]

10) Cao H, Li X, Liu J: An updated review of the efficacy of cupping therapy. PLoS One, 2012, 7: e31793. [Medline] [CrossRef]

11) Tagil SM, Celik HT, Ciftci S, et al.: Wet-cupping removes oxidants and decreases oxidative stress. Complement Ther Med, 2014, 22: 1032-1036. [Medline] [CrossRef]

12) Farahmand SK, Gang LZ, Saghebi SA, et al.: The effects of wet cupping on serum high-sensitivity C-reactive protein and heat shock protein 27 antibody titers in patients with metabolic syndrome. Complement Ther Med, 2014, 22: 640-644. [Medline] [CrossRef]

13) Chi LM, Lin LM, Chen CL, et al.: The effectiveness of cupping therapy on relieving chronic neck and shoulder pain: a randomized controlled trial. Evid Based Complement Alternat Med, 2016, 2016: 7358918. [Medline] [CrossRef]

14) Vladimirov YA, Osipov AN, Klebanov GI: Photobiological principles of therapeutic applications of laser radiation. Biochemistry (Mosc), 2004, 69: 81-90. [Medline] [CrossRef]

15) Chow RT, David MA, Armati PJ: $830 \mathrm{~nm}$ laser irradiation induces varicosity formation, reduces mitochondrial membrane potential and blocks fast axonal flow in small and medium diameter rat dorsal root ganglion neurons: implications for the analgesic effects of $830 \mathrm{~nm}$ laser. J Peripher Nerv Syst, 2007, 12: 28-39. [Medline] [CrossRef]

16) Hagiwara S, Iwasaka H, Okuda K, et al.: GaAlAs ( $830 \mathrm{~nm}$ ) low-level laser enhances peripheral endogenous opioid analgesia in rats. Lasers Surg Med, 2007, 39: 797-802. [Medline] [CrossRef]

17) Castano AP, Dai T, Yaroslavsky I, et al.: Low-level laser therapy for zymosan-induced arthritis in rats: importance of illumination time. Lasers Surg Med, 2007, 39: 543-550. [Medline] [CrossRef]

18) Paolillo FR, Arena R, Dutra DB, et al.: Low-level laser therapy associated with high intensity resistance training on cardiac autonomic control of heart rate and skeletal muscle remodeling in Wistar rats. Lasers Surg Med, 2014, 46: 796-803. [Medline] [CrossRef] 